\title{
The creation of the International Federation of Human Genetics Societies in 1995-1996
}

\author{
Marcus Pembrey \\ European Journal of Human Genetics (2017) 25, S43-S44; doi:10.1038/ejhg.2017.153
}

In many ways, the 'time was ripe' for the creation of an International Federation of Human Genetics Societies (IFHGS) in the mid 1990s. The human genome project was underway, supported by the Human Genome Organization (HUGO) that emerged in 1988 from the gene mapping meetings. HUGO holds international meetings and has a committee on Ethics, Law and Society, but did not deal directly with the provision of genetic services and the issues that arise in clinical practice and genetic counselling. The ESHG had its own Ethics Committee, renamed the Public and Professional Policy Committee, that I chaired from 1994 to 1998, and this worked to develop and harmonise practice guidelines within Europe. There was naturally quite a bit of discussion with the colleagues around the world, and we usually attended the annual meeting of the American Society of Human Genetics (ASHG). From a global perspective, the World Health Organisation (WHO) had an active interest, but the only worldwide forum for human geneticists was the 5 yearly International Congress of Human Genetics (ICHG) run by the self-styled Permanent Committee. The name says it all! It was considered by many, including some of its members, to be both impenetrable and undemocratic. I was the president of the ESHG in 1994-1995, a time when dissatisfaction with the Permanent Committee was running high during the lead up to the 9th International Congress on Human Genetics in Rio de Janeiro to be held in August 1996. The Committee rules had established that the benefits of the congresses were for the Permanent Committee and the losses, if any, for the local organisers. With the meeting taking place in Brazil, a developing country, many felt they should not have to bear the burden of any losses.

This was the background, but what finally triggered the launch of the IFHGS was a WHO, 90-page document, Guidelines on Ethical Issues on Medical Genetics and the Provision of Genetic Services. ${ }^{1}$ This was written by two ethicists, Dorothy Wertz and John Fletcher, Kåre Berg a medical geneticist who presided over the Permanent Committee, and Victor Boulyjenkov, employed by the WHO on the Hereditary Diseases Programme in the Division of Noncommunicable Diseases, also a member of the Permanent Committee. Officers of the ESHG and ASHG had arranged an informal breakfast meeting during the 1995 ASHG Annual Conference in Minneapolis, Minnesota, USA. Ségolène Aymé, Jean-Jacques Cassiman and I represented the ESHG and as I recall Judy Hall (President), Maimon Cohen (immediate past President) and Elaine Strass (Executive Director) were among those from the ASHG. When I produced a draft copy of the 'WHO Guidelines', as Dorothy Wertz was calling them, it was quite clear that the ASHG people knew nothing of this document. The sense of indignation was palpable - particularly regarding the inclusion of genetic services. Who were they to speak for the experienced medical and clinical practitioners represented by their national and multinational professional societies around the world? We immediately considered how to counter this - and I sensed we were pushing at an open door. Maimon Cohen had previously discussed with me a need for coordination between the established 'continental' human genetics societies and had even thought of a snappy name 'COPS' - Committee of Presidents of (human genetic) Societies. The idea of an international federation had also been mooted. It was going to take a lot of work and commitment - would we in the ESHG take it on? We said yes, and that was essentially the end of the meeting. I suspect the fact that Vienna was in line for the 2001 International Congress of Human Genetics was influential in the ESHG being asked to launch the IFHGS, but as I recall, at the time, the question of the IFHGS taking over from the Permanent Committee was put on hold - one step at a time. There were many other factors at play and it was particularly valuable that Judy Hall was then president of the ASHG. She and Elaine Strass were extremely committed and helpful.

There were aspects in which I was less directly involved. I do not really know the chain of events that led to the IFHGS taking over from the Permanent Committee, but was aware of the 'fall out' that has been described elsewhere. ${ }^{2}$ Ségolène Aymé was succeeding me as the president of the ESHG and with it, the 3-year term as the president of the new IFHGS dedicated to 'providing a transparent structure to facilitate communication throughout the international community of human geneticists'. Before working with Ségolène, Jean-Jacques and others on the draft IFHGS statutes, we had to find a structure that would function from the beginning. We essentially made pragmatic suggestions that built on the existing well-established (and funded) professional societies. We could not have a costly stand-alone organisation, and settled on the idea of the 'continental' societies being Full Members and individual national societies being Corresponding Members, for purely practical reasons. Full Members were few in number and their IFHGS representatives could be supported to travel to regular meetings. The initial Full Members were ASHG, ESHG and the Human Genetics Societies of Australasia (HGSA) through the good offices of Agnes Bankier and others. Working to encourage continental alliances, where these did not yet exist was, in my view, valuable in itself; and not just because one aim was to facilitate Full Membership of the IFHGS. It was part of getting to know the international community of human geneticists - and the different challenges we faced. The first additional Full Member was the Latin-American network society RELAGH (Red Latinoamericana de 
Genetica Humana) established in 2001 through the efforts of Dr Jose M Cantu (Mexico), Dr Roberto Giugliani (Brazil), Dr Alejandro Giraldo (Colombia) and others. This activity resulted in my having a memorable trip to Bogota to speak at the Fifth Colombian Genetics Congress in April 2002 at the invitation of Alejandro Giraldo. It was straight from the last talk of the day to the dance floor - the salsa or similar! But by this time, I had handed over the IFHGS liaison role to Jean-Jacques Cassiman.

What about those WHO guidelines? Fifteen WHO advisers from developed and developing nations met and revised the guidelines. The much shorter document (16 pages) was published in May 1998 as 'Proposed International Guidelines on the Ethical Issues on Medical
Genetics and Genetic Services'. For the IFHGS and ESHG, the real legacy of the 'guideline saga' was that it encouraged Ségolène Aymé to seek EU funding for what was EUROGAPPP, through which she and others did excellent work over several years on various professional guidelines.

1 Wertz DC et al: Guidelines on Ethical Issues on Medical Genetics and the Provision of Genetic Services. WHO: Geneva, Switzerland, 1995.

2 Karen Birmingham. Foundation of the International Federation of Human Genetic Societies: the Catalyst. In: Heike P, Peter H, Susanne D (eds). History of Human Genetics. Important Discoveries and Global Perspectives 2017.

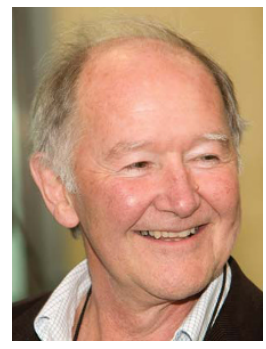

Marcus Pembrey

A biography of this author appears earlier in this issue. 